\title{
Penerapan Algoritma Sweep Dalam Perencanaan Pendistribusian Produk Roti di Wilayah Kota Yogyakarta
}

\author{
Yohanes Anton Nugroho', Rolis Andika Yatmoko ${ }^{2)}$ \\ ${ }^{1,2)}$ Fakultas Sains dan Teknologi, Jurusan Teknik Industri, Universitas Teknologi Yogyakarta \\ Jl. Glagahsari 63 Yogyakarta, 55164 \\ E-mail: yohanesanton@uty.ac.id, rolis.andika02@gmail.com
}

\begin{abstract}
ABSTRAK
Tujuan dari penelitian ini adalah untuk membuat solusi baru untuk distribusi produk Sari Roti di CV Jogja Transport. CV Jogja Transport mengantarkan produk roti baru dan mengambil produk-produk yang tidak terjual akan diganti dengan produk-produk baru. CV Jogja Transport memiliki empat karyawan yang melayani sebagai distribusi produk Sari Roti di kota Yogyakarta. Mereka memiliki sistem kerja bergulir dengan jam kerja mulai pukul 06.00 WIB hingga 12.00 WIB. Terbatasnya kapasitas kendaraan dan waktu pengiriman yang disarankan menyebabkan pengiriman tidak sesuai dengan rencana. Dalam tulisan ini, kami menunjukkan aplikasi dari Algoritma Sapu untuk menghasilkan rute distribusi baru. Pertimbangkan aturan distribusi dan sumber daya; Algoritma Sapu mencoba membawa cluster distribusi baru dan tugas penjualan. Solusi ini mengurangi jarak dari gudang CV Jogja Transport ke setiap lokasi toko yang 115,39 Km menjadi 64,3 Km. Solusi ini juga mengurangi waktu pengiriman dari 1143,49 menit menjadi 1032,11 menit. Pengurangan jarak dan biaya juga akan mengurangi 56,48\% biaya distribusi dari Rp.56.539 menjadi Rp. 31.717.
\end{abstract}

Kata kunci: Distribusi, algoritma sweep, penugasan sales, waktu pengiriman, biaya pengiriman

\begin{abstract}
The purpose of this research is to create a new solution for the distribution of Sari Roti products at CV Jogja Transport. CV Jogja Transport delivers fresh bread products and takes the unsold products. CV Jogja Transport has four employees serving as courier Sari Roti products in municipality Yogyakarta. They have a rolling work system with working hours starting at $06.00 \mathrm{WIB}$ until $12.00 \mathrm{WIB}$. The limited capacity of the vehicle and the recommended delivery time cause the delivery is not according to plan. In this paper, we show an application of the Sweep Algorithm to generate new distribution routes. Consider the rules of distribution and resources; the Sweep Algorithm tried to bring a new distribution cluster and sales assignment. This solution reduced the distance from the CV Jogja Transport warehouse to each store location that 115,39 $\mathrm{Km}$ to $64,3 \mathrm{Km}$. This solution also reduced delivery time from 1143,49 minutes to 1032,11 minutes. Reduction in distance and costs also will reduce 56,48\% distribution costs from Rp.56.539 to $R$. 31.717.
\end{abstract}

Keywords: Distribution, sweep algorithm, sales assignment, delivery times, distribution cost.

\section{PENDAHULUAN}

CV Jogja Transport adalah distributor resmi dari produk Sari Roti di wilayah kotamadya Yogyakarta. Proses distribusi produk dilakukan secara terus menerus, dari lokasi menuju mitra. Apabila produk tidak terjual sampai dengan masa kedaluwarsa, maka akan di ganti dengan produk yang baru. Kondisi ini menyebabkan perusahaan harus dapat mengantarkan produk Sari Roti dengan mempertimbangkan masa kedaluwarsa.

Pendistribusian produk roti dilakukan dengan sepeda motor bebek yang dilengkapi box di bagian belakang. Masing-masing box dapat menampung produk sekitar 450 buah roti. CV Jogja Transport memiliki 4 orang karyawan yang bertugas sebagai distributor dengan sistem kerja rolling dengan waktu jam kerja dimulai pukul 06.00 WIB hingga 12.00 WIB.

Besarnya permintaan pasar dan waktu pendistribusian yang singkat, serta waktu kedaluwarsa produk yang relatif singkat menjadikan kendala tersendiri bagi perusahaan. Salah satu masalah yang dihadapi adalah 
keterlambatan pengiriman karena keterbatasan kendaraan angkut. Selain itu pendistribusian juga mempertimbangkan waktu pengiriman, dimana pengiriman tidak dilakukan melebihi jam 12.00 WIB.

Penumpukan dan keterlambatan pengiriman produk dari distributor hingga sampai di konsumen. Perusahaan harus memperhatikan time liness of delivery atau ketepatan waktu pengiriman, karena ketepatan waktu pengiriman sangat mempengaruhi kualitas produk dikarenakan produk roti tersebut memiliki masa kedaluwarsa yang singkat sehingga perlu adanya upaya untuk memaksimalkan pendistribusian produk dalam mempertahankan kualitas produk agar tetap terjaga hingga sampai ke konsumen dan pelanggannya tanpa mengenyampingkan pengeluran perusahaan untuk bidang pendistribusian produk tersebut.

Secara umum permasalahan dalam pendistribusian yang dihadapi oleh perusahaan dapat dikategorikan sebagai masalah Vehicle Routing Problem (VRP), dimana permintaan transportasi yang akan dilayani umumnya terkonsentrasi di titik-titik tertentu dari suatu jaringan jalan, di mana permintaan tersebar di sepanjang busur, yaitu segmen jalan dari jaringan jalan yang mendasarinya. Komponen VRP, yang merupakan permintaan transportasi dan bagaimana mereka dapat dilakukan, armada kendaraan, biaya dan keuntungan terkait (jika relevan), dan kelayakan rute (Irnich et al., 2014).

Penentuan rute distribusi pada umumnya dilakukan dengan mempertimbangkan beberapa hal. Beberapa penelitian terkait pengembangan rute untuk meminimalkan jarak dan meminimalkan biaya antara lain dilakukan oleh [2]-[12] Diantara penelitian-penelitian tersebut yang mencoba menerapkan algoritma Sweep diantaranya adalah (Cahyaningsih et al., 2015; Dondo \& Cerdá, 2013; Saraswati et al., 2017).

Algoritma Sweep diharapkan dapat menjabarkan mengenai bagaimana merencanakan pendistribusian yang sesuai agar pendistribusian produk dari distributor ke konsumen dapat berjalan lancar dan dapat meminimalisir pengeluran biaya perusahaan.

\section{METODE PENELITIAN}

\subsection{Obyek dan Subyek Penelitian}

Subyek penelitian ini adalah bagian pendistribusian barang di CV Jogja Transport yang berfokus pada pendistribusian produk Sari Roti di area kota Yogyakarta dan sekitarnya. Subyek penelitian berlokasi di Jl. SMP 10, Bangunharjo, Sewon, Bantul, Daerah Istimewa Yogyakarta.

Obyek penelitian ini adalah proses pendistribusian produk-produk Sari Roti dari gudang CV Jogja Transport menuju ke sejumlah lokasi pemasaran.

\subsection{Data}

Metode-metode yang digunakan dalam pengumpulan data diantaranya dengan melakukan pengamatan dan pengukuran langsung dilapangan, melalui wawancara dengan supervisor, team distribusi, dan driver. Dalam penelitian ini didapatkan sejumlah data yang digunakan dalam penelitian, yaitu adalah sebagai berikut:

1. Data Primer

Data primer yang didapatkan melalui pengamatan dan pengukuran langsung diantaranya adalah:

a. Data kapasitas kendaraan

b. Ddata lokasi toko

c. Data alokasi kendaraan ke toko

d. Data rute kendaraan awal

e. Data kebutuhan waktu loading dan unloading

2. Data Sekunder

Data sekunder yang didapatkan dalam penelitian ini diantaranya adalah:

a. Data permintaan

b. Data bahan bakar

c. Data biaya transportasi.

d. Data jumlah salses untuk pedistribusian.

\subsection{Tahapan Penelitian}

Penelitian ini dilakukan dengan melalui sejumlah tahapan seperti ditunjukkan pada Gambar 1. 


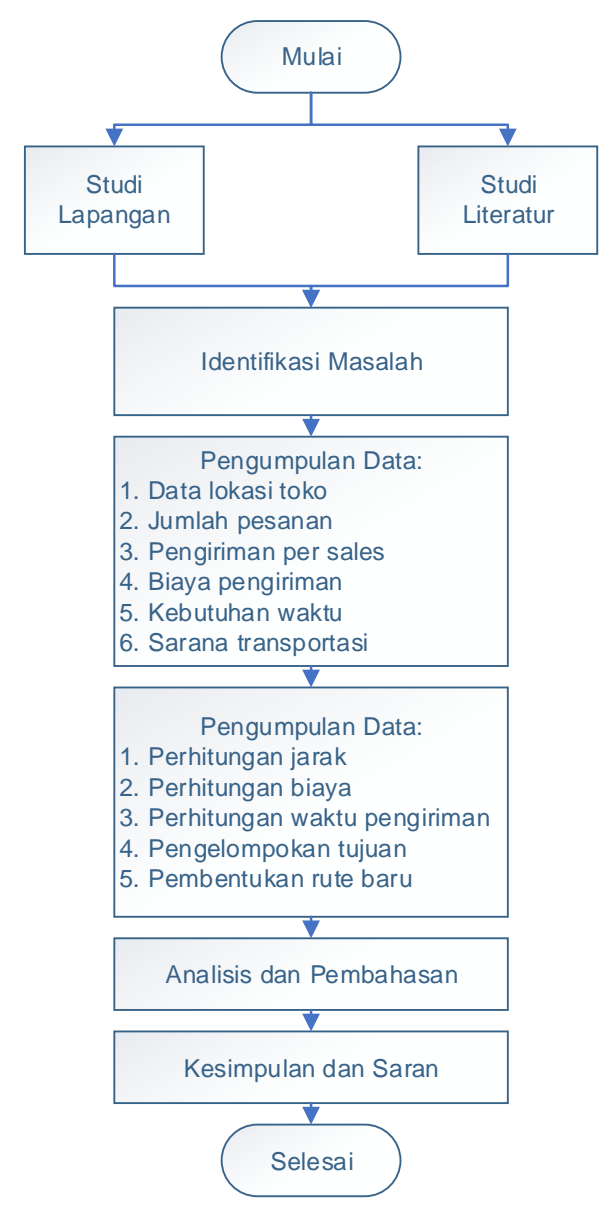

Gambar 1. Diagram Alir Penelitian

Pengumpulan data dilakukan melalui observasi, dilanjutkan dengan interview/wawancara supervisor, team distribusi, dan driver.Tahap-tahapan dalam pengolahan data adalah sebagai berikut:

1. Mengidentifikasi Jarak kirim.

Mengidentifikasi jarak kirim dilakukan dengan perhitungan kalkulasi azimuth, lalu dilanjutkan membuat matrik untuk diuji, uji matrik jarak dilakukan untuk melihat jarak depot ke setiap toko-toko yang dilalui oleh kendaraan.

2. Menentukan biaya kirim

Penentuan biaya kirim yang dikeluarkan perusahaan untuk sekali jalan dengan

3. Menentukan total waktu pengiriman

Yaitu perhitungan waktu yang digunkan untuk sekali pengiriman dengan rumus

4. Mengelompokkan toko dengan metode Algoritma Sweep

Tahap pertama dalam algoritma sweep adalah mengelompokkan masing-masing titik agen ke dalam sebuah cluster.

5. Tahap Pembentukan Rute

Masing-masing cluster $=$ akan diselesaikan dengan menggunakan metode Algoritma Sweep sehingga dapat diperoleh urutan rute perjalanan dari masing-masing cluster. Selanjutnya dapat diperoleh jumlah toko yang dikunjungi dalam satu rute, total biaya bahan bakar,waktu perjalanan dan jumlah muatan untuk tiap rute.

\section{HASIL DAN PEMBAHASAN} Tabel 1.

Pengiriman roti dari CV Jogja Transport dilakukan dilakukan menuju 49 titik, seperti ditunjukkan pada 
Tabel 1. Data distribusi pengiriman per sales

\begin{tabular}{|c|c|c|c|c|c|}
\hline No & $\begin{array}{l}\text { Kode } \\
\text { Toko }\end{array}$ & Nama Toko & Kecamatan & Koordinat & $\begin{array}{c}\text { Jumlah } \\
\text { Pesanan }\end{array}$ \\
\hline 1 & T1 & Toko 32 & Mantrijeron & $7^{\circ} 49^{\prime} 32.5^{\prime \prime S} 110^{\circ} 22^{\prime} 40.5^{\prime \prime E}$ & 41 \\
\hline 2 & $\mathrm{~T} 2$ & Amanah PKU & Ngampilan & $7^{\circ} 48^{\prime} 03.8^{\prime \prime S} 110^{\circ} 21^{\prime} 43.5^{\prime \prime E}$ & 80 \\
\hline 3 & $\mathrm{~T} 3$ & SMA MAN 2 Yogyakarta & Ngampilan & $7^{\circ} 48^{\prime} 03.2^{\prime \prime S} 110^{\circ} 21^{\prime} 24.7^{\prime \prime E}$ & 20 \\
\hline 4 & $\mathrm{~T} 4$ & SMP N 7 Yogyakarta & Tegal Rejo & $7^{\circ} 47^{\prime} 28.2^{\prime \prime S} 110^{\circ} 21^{\prime} 03.4^{\prime \prime E}$ & 40 \\
\hline 5 & T5 & Kafetaria AMC & Wirobrajan & $7^{\circ} 47^{\prime} 57.7^{\prime \prime S} 110^{\circ} 21^{\prime} 07.0^{\prime \prime} \mathrm{E}$ & 15 \\
\hline 6 & T6 & 5 Mart & Ngampilan & $7^{\circ} 48^{\prime} 03.0^{\prime \prime S} 110^{\circ} 21^{\prime} 24.3^{\prime \prime E}$ & 17 \\
\hline 7 & $\mathrm{~T} 7$ & $\begin{array}{l}\text { Kantin Stela Duce } 1 \text { Kota } \\
\text { Baru }\end{array}$ & Gondokusuman & $7^{\circ} 47^{\prime} 02.0^{\prime \prime S} 110^{\circ} 22^{\prime} 18.3^{\prime \prime E}$ & 65 \\
\hline 8 & $\mathrm{~T} 8$ & Kantin SMA N 4 Yogyakarta & Tegalrejo & $7^{\circ} 46^{\prime} 18.1^{\prime \prime S} 110^{\circ} 21^{\prime} 44.9^{\prime \prime E}$ & 35 \\
\hline 9 & T9 & Toko Suhadi & Tegalrejo & $7^{\circ} 46^{\prime} 33.8^{\prime \prime S} 110^{\circ} 21^{\prime} 10.2^{\prime \prime E}$ & 42 \\
\hline 10 & $\mathrm{~T} 10$ & Kantin SMA 11 Yogyakarta & Jetis & $7^{\circ} 46^{\prime} 38.0^{\prime \prime S} 110^{\circ} 22^{\prime} 05.1^{\prime \prime} \mathrm{E}$ & 30 \\
\hline 11 & T11 & Omi Kopegtel & Mergangsan & $7^{\circ} 48^{\prime} 43.5^{\prime \prime S} 110^{\circ} 22^{\prime} 19.3 " \mathrm{E}$ & 15 \\
\hline 12 & $\mathrm{~T} 12$ & Toko Tomo & Umbulharjo & $7^{\circ} 49^{\prime} 27.6^{\prime \prime S} 110^{\circ} 22 ' 31.3^{\prime \prime E}$ & 18 \\
\hline 13 & $\mathrm{~T} 13$ & MM kokarda RS Bethesda & Gondokusuman & $7^{\circ} 47^{\prime} 00.1^{\prime \prime S} 110^{\circ} 22^{\prime} 42.6^{\prime \prime E}$ & 95 \\
\hline 14 & T14 & Twins Mart & Gedong Tengen & $7^{\circ} 47^{\prime} 22.8^{\prime \prime S} 110^{\circ} 21^{\prime} 32.9^{\prime \prime} \mathrm{E}$ & 66 \\
\hline 15 & $\mathrm{~T} 15$ & Pamella 1 & Umbulharjo & $7^{\circ} 48^{\prime} 05.7^{\prime \prime S} 110^{\circ} 23^{\prime} 27.8^{\prime \prime E}$ & 155 \\
\hline 16 & $\mathrm{~T} 16$ & Pamella 4 & Umbulharjo & $7^{\circ} 49^{\prime} 26.8^{\prime \prime S} 110^{\circ} 23^{\prime} 24.1^{\prime \prime} \mathrm{E}$ & 81 \\
\hline 17 & $\mathrm{~T} 17$ & Toko Progo & Gondokusuman & $7^{\circ} 47^{\prime} 50.4^{\prime \prime S} 110^{\circ} 22^{\prime} 09.3^{\prime \prime E}$ & 56 \\
\hline 18 & $\mathrm{~T} 18$ & Citrouli 2 & Gondokusuman & $7^{\circ} 46^{\prime} 59.5^{\prime \prime S} 110^{\circ} 23^{\prime} 18.9^{\prime \prime E}$ & 70 \\
\hline 19 & T19 & Pamella 8 & Umbulharjo & $7^{\circ} 49^{\prime} 26.8^{\prime \prime S} 110^{\circ} 22^{\prime} 51.3 " \mathrm{E}$ & 95 \\
\hline 20 & $\mathrm{~T} 20$ & Pamella 2 & Umbulharjo & $7^{\circ} 48^{\prime} 46.3^{\prime \prime S} 110^{\circ} 23^{\prime} 29.0^{\prime \prime E}$ & 69 \\
\hline 21 & $\mathrm{~T} 21$ & VIVO Mini Market & Gondokusuman & $7^{\circ} 46^{\prime} 47.0^{\prime \prime} \mathrm{S} 110^{\circ} 22^{\prime} 47.3^{\prime \prime} \mathrm{E}$ & 63 \\
\hline 22 & $\mathrm{~T} 22$ & Gardena & Gondokusuman & $7^{\circ} 46^{\prime} 59.5^{\prime \prime S} 110^{\circ} 22^{\prime} 52.8^{\prime \prime} \mathrm{E}$ & 158 \\
\hline 23 & $\mathrm{~T} 23$ & Jogja Mart & Mergangsan & $7^{\circ} 49^{\prime} 12.4^{\prime \prime S} 110^{\circ} 22^{\prime} 12.1^{\prime \prime E}$ & 81 \\
\hline 24 & $\mathrm{~T} 24$ & Loco & Gondokusuman & $7^{\circ} 46^{\prime} 57.1^{\prime \prime S} 110^{\circ} 22^{\prime} 39.2^{\prime \prime} \mathrm{E}$ & 41 \\
\hline 25 & $\mathrm{~T} 25$ & Ramai Mall & Gondomanan & $7^{\circ} 47^{\prime} 12.4^{\prime \prime S} 110^{\circ} 22^{\prime} 38.5^{\prime \prime E}$ & 84 \\
\hline 26 & $\mathrm{~T} 26$ & Hotel Puri Pangeran & Pakualaman & $7^{\circ} 47^{\prime} 05.2^{\prime \prime S} 110^{\circ} 23^{\prime} 08.2^{\prime \prime} \mathrm{E}$ & 7 \\
\hline 27 & $\mathrm{~T} 27$ & Kopma UAD & Umbulharjo & $7^{\circ} 47^{\prime} 09.8^{\prime \prime S} 110^{\circ} 23^{\prime} 26.6^{\prime \prime} \mathrm{E}$ & 55 \\
\hline 28 & $\mathrm{~T} 28$ & Kopsis Boda SMA Bopkri 2 & Gondokusuman & $7^{\circ} 47^{\prime} 00.1^{\prime \prime S} 110^{\circ} 23^{\prime} 07.7^{\prime \prime E}$ & 25 \\
\hline 29 & $\mathrm{~T} 29$ & Kantin Borju SMA Bopkri 1 & Gondokusuman & $7^{\circ} 46^{\prime} 43.5^{\prime \prime S} 110^{\circ} 22^{\prime} 30.8^{\prime \prime} \mathrm{E}$ & 34 \\
\hline 30 & $\mathrm{~T} 30$ & Kopma Ista & Gondokusuman & $7^{\circ} 47^{\prime} 14.0^{\prime \prime S} 110^{\circ} 22^{\prime} 33.4^{\prime \prime E}$ & 35 \\
\hline 31 & $\mathrm{~T} 31$ & Kantin Fatin & Gondokusuman & $7^{\circ} 47^{\prime} 14.0^{\prime \prime S} 110^{\circ} 22^{\prime} 35.4^{\prime \prime} \mathrm{E}$ & 40 \\
\hline 32 & T32 & Anda Jaya & Gondokusuman & $7^{\circ} 46^{\prime} 53.4^{\prime \prime S} 110^{\circ} 22^{\prime} 37.4^{\prime \prime E}$ & 50 \\
\hline 33 & $\mathrm{~T} 33$ & Kantin SMA Budya Wacana & Gondokusuman & $7^{\circ} 46^{\prime} 51.0^{\prime \prime} \mathrm{S} 110^{\circ} 22^{\prime} 30.8^{\prime \prime} \mathrm{E}$ & 44 \\
\hline
\end{tabular}

Rute pengiriman awal untuk masing-masing sales adalah sebagai berikut:

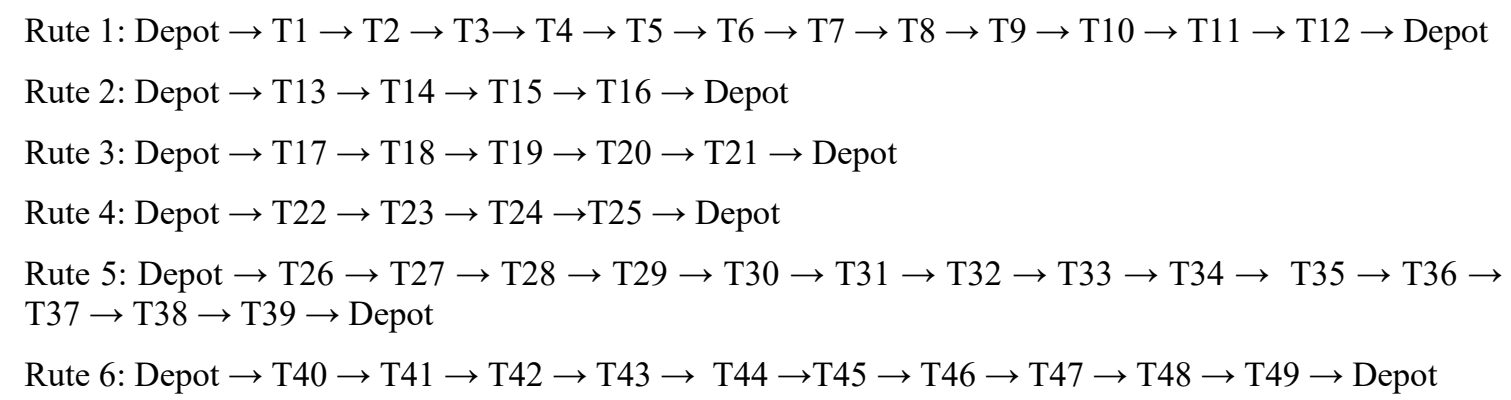

Penentuan rute menggunakan algoritma sweep dilakukan melalui sejumla tahapan, yaitu:

1. Identifikasi Jarak Pengiriman dari Depot

Perhitungan jarak menggunakan kalkulasi azimuth dengan cara mengkonversikan jarak dari koordinat awal (depot) menuju koordinat tujuan yang menjadi jarak dalam satuan kilometer. Hasilnya ditunjukkan pada Tabel 2 . 
Tabel 2. Jarak Pengiriman

\begin{tabular}{cccccc}
\hline Kode & $\begin{array}{c}\text { Jarak } \\
(\mathrm{km})\end{array}$ & Kode & $\begin{array}{c}\text { Jarak } \\
(\mathrm{km})\end{array}$ & Kode & $\begin{array}{c}\text { Jarak } \\
(\mathrm{km})\end{array}$ \\
\hline T1 & 0,39 & T15 & 3,12 & T29 & 4,18 \\
T2 & 2,94 & T16 & 1,70 & T30 & 4,88 \\
T3 & 3,26 & T17 & 3,06 & T31 & 4,61 \\
T4 & 3,40 & T18 & 4,82 & T32 & 4,70 \\
T5 & 3,74 & T19 & 0,70 & T33 & 5,06 \\
T6 & 3,27 & T20 & 2,25 & T34 & 4,12 \\
T7 & 4,50 & T21 & 4,98 & T35 & 4,13 \\
T8 & 6,00 & T22 & 4,63 & T36 & 4,76 \\
T9 & 5,87 & T23 & 0,70 & T37 & 4,83 \\
T10 & 5,27 & T24 & 3,24 & T38 & 5,32 \\
T11 & 1,40 & T25 & 3,22 & T39 & 2,60 \\
T12 & 0,09 & T26 & 2,64 & T40 & 2,91 \\
T13 & 4,57 & T27 & 1,56 & T41 & 2,73 \\
T14 & 4,21 & T28 & 6,37 & T42 & 4,46 \\
\hline
\end{tabular}

2. Menentukan Biaya Pengiriman

Kebutuhan biaya distribusi dihitung berdasarkan jarak berangkat dari depot hingga pulang kembali ke depot, dalam hal ini jarak dari depot menuju toko hingga kembali lagi ke depot dihitung sekali jalan dengan harga bahan bakar pada saat penelitian dilakukan, yaitu $\mathrm{Rp} 7350 /$ liter.

Sebagai asumsi konsumsi bahan bakar kendaraan, digunakan 1 liter pertalite digunakan untuk perjalanan 15 Kilometer, dikarenakan muatan barang lebih berat dari standar kendaraan roda dua selain itu kendaraan sering berhenti dan melanjutnya perjalanan, hal ini dapat menambah jumlah konsusi bahan bakar dikarenakan proses Stop and Go pada putaran gas awal kendaraan membutuhkan lebih banyak asupan bahan bakar pada ruang bakar mesin.

3. Menentukan Total Waktu Pengiriman

Kebutuhan waktu operasional penyaluran produk didsarkan pada waktu yang dibutuhkan untuk operasional kendaraam, yaitu waktu perjalanan dari kendaaran berangkat hingga kendaraan sampai kembali ke depot dengan mempertimbangkan jarak, serta waktu untuk menata barang ke dalam box kendaraan (loading) dan waktu bongkar muatan di tiap tiap toko (unloading).

Berdasarkan pengamatan Waktu loading dan undloading, dimana waktu loading 40 menit dan waktu unloading 15 menit pertoko.

\section{Tahap Clustering (Pengelompokan)}

Langkah penggunaan Algoritma Sweep tahap pertama yaitu pengelompokan seluruh toko tujuan dengan menggunakan matriks jarak total. Algoritma Sweep melakukan pencarian pelanggan terdekat dengan pelanggan yang terakhir untuk ditambahkan pada akhir rute tersebut dengan batasan kapasitas muatan 450 bungkus roti dan waktu perjalanan selama 6 jam.

Langkah ini memastikan semua toko yang akan dikunjungi "tersapu" dalam cluster saat ini. Langkah pengelompokkan akan dihentikan apabila kapasitas maksimal kendaraan sudah terpenuhi atau mendekati Langkah ini berawal dari mencari toko terdekat dari depot. Setelah ditentukan toko pertama selanjutnya dilakukan pemilihan berikutnya yang dekat dengan toko tersebut. Hasilnya didapatkan rute pendistribusian pertama adalah:

$\mathrm{Depot} \rightarrow \mathrm{T} 12 \rightarrow \mathrm{T} 1 \rightarrow \mathrm{T} 19 \rightarrow \mathrm{T} 27 \rightarrow \mathrm{T} 30 \rightarrow \mathrm{T} 22 \rightarrow \mathrm{T} 33 \rightarrow$ Depot

Langkah tersebut diulangi hingga semua toko dikunjungi dengan batasan 6 jam kerja perhari atau muatan 450 bungkus, apabila telah mencapai salah satu batasan maka rute ditutup dan pengiriman kembali ke depot dilanjutkan membuat rute baru yang diawali dari depot dengan menghapus toko-toko yang telah dikunjungi di rute sebelumnya.

5. Tahap Pembentukan Rute Baru

Pada tahap pembentukan rute, masing-masing cluster yang telah diperoleh pada tahapan sebelumnya akan diselesaikan sehingga dapat diperoleh urutan rute perjalanan dari masing-masing cluster. Hasil pencarian rute baruBerdasarkan hasil pengolahan data pada tahap sebelumnya, maka dapat dibentuk rute pendistrian yang baru sebagai berikut: 
Rute I: Depot $\rightarrow \mathrm{T} 12 \rightarrow \mathrm{T} 1 \rightarrow \mathrm{T} 19 \rightarrow \mathrm{T} 27 \rightarrow \mathrm{T} 30 \rightarrow \mathrm{T} 22 \rightarrow \mathrm{T} 33 \rightarrow$ Depot

Rute II: Depot $\rightarrow \mathrm{T} 23 \rightarrow \mathrm{T} 11 \rightarrow \mathrm{T} 39 \rightarrow \mathrm{T} 26 \rightarrow \mathrm{T} 41 \rightarrow \mathrm{T} 40 \rightarrow \mathrm{T} 17 \rightarrow \mathrm{T} 25 \rightarrow \mathrm{T} 2 \rightarrow \mathrm{T} 3 \rightarrow \mathrm{T} 6 \rightarrow \mathrm{T} 5 \rightarrow \mathrm{T} 10 \rightarrow$ Depot

Rute III: Depot $\rightarrow \mathrm{T} 46 \rightarrow \mathrm{T} 20 \rightarrow \mathrm{T} 49 \rightarrow \mathrm{T} 48 \rightarrow \mathrm{T} 15 \rightarrow \mathrm{T} 44 \rightarrow \mathrm{T} 45 \rightarrow \mathrm{T} 16 \rightarrow$ Depot

Rute IV: Depot $\rightarrow \mathrm{T} 47 \rightarrow \mathrm{T} 43 \rightarrow \mathrm{T} 24 \rightarrow \mathrm{T} 32 \rightarrow \mathrm{T} 18 \rightarrow \mathrm{T} 31 \rightarrow \mathrm{T} 42 \rightarrow \mathrm{T} 13 \rightarrow \mathrm{T} 37 \rightarrow \mathrm{T} 34 \rightarrow$ Depot

Rute V: Depot $\rightarrow \mathrm{T} 4 \rightarrow \mathrm{T} 14 \rightarrow \mathrm{T} 21 \rightarrow \mathrm{T} 35 \rightarrow \mathrm{T} 29 \rightarrow \mathrm{T} 28 \rightarrow \mathrm{T} 36 \rightarrow \mathrm{T} 38 \rightarrow \mathrm{T} 7 \rightarrow \mathrm{T} 8 \rightarrow \mathrm{T} 9 \rightarrow$ Depot

Selanjutnya berdasarkan rute yang dihasilkan jarak dan muatan yang dibebankan pada masing-masing rute baru dari depot CV Jogja Transport ditunjukkan pada Tabel 3.

Tabel 3. Perbandingan jarak dan muatan

\begin{tabular}{lccc}
\hline No & Rute & Jarak $(\mathrm{Km})$ & Muatan \\
\hline 1 & I & 8,36 & 446 \\
2 & II & 14,92 & 447 \\
3 & III & 9,15 & 449 \\
4 & IV & 15,48 & 449 \\
5 & V & 16,82 & 442 \\
\hline
\end{tabular}

Kebutuhan biaya distribusi dihitung berdasarkan jarak berangkat dari depot hingga pulang kembali Jarak dari depot menuju toko hingga kembali lagi ke depot dihitung sekali jalan dengan harga bahan bakar (pertalite) sesuai pada saat dilakukan penelitian, yaitu Rp. 7.450 per liter

Sebagai contoh jarak yang ditempuh untuk rute 1 adalah $8,36 \mathrm{~km}$. Dengan rata-rata kebutuhan bahan bakar 1 liter bahan bakar dapat digunakan untuk jarak 15 KM, maka dapat dihitung biaya pembelian bahan bakar rute 1 adalah:

Biaya distribusi $=\frac{8,36 \mathrm{~km}}{15 \mathrm{~km} / \mathrm{l}} \times R p 7.450 / l$
Biaya distribusi $=R p 4.097$

Hasil perhitungan biaya distribusi untuk semua rute ditunjukkan Tabel 4.

Tabel 4. Biaya Distribusi

\begin{tabular}{ccc}
\hline No & Rute & Biaya Distribusi (Rp) \\
\hline 1 & I & 4.097 \\
2 & II & 7.310 \\
3 & III & 4.483 \\
4 & IV & 7.585 \\
5 & V & 8.242 \\
& Total & 31.717 \\
\hline
\end{tabular}

Kebutuhan waktu penyaluran produk didasarkan pada waktu waktu perjalanan, waktu untuk menata barangke dalam box kendaraan (loading) serta waktu bongkar muatan di tiap tiap toko (unloading).

Berdasarkan data pengamatan awal, waktu yang dibutuhkan untuk melakukan proses loading roti ke kendaraan membutuhkan waktu 40 menit, sementara waktu yang dibutuhkan untuk membongkar dan melakukan proses transaksi pada masing-masing toko tujuan adalah 15 menit/tujuan.

Sebagai contoh pada rute 1 , perhitungan kebutuhan waktunya adalah sebagai berikut

Waktu perjalanan $=\frac{\text { Jarak }}{\text { Kecepatan }} \times 60$ menit

Waktu perjalanan $=\frac{8,36 \mathrm{~km}}{40 \mathrm{~km} / \mathrm{jam}} \times 60$ menit

Waktu perjalanan $=12,54$ menit

Hasil diatas adalah waktu kendaraan dalam perjalanan maka harus ditambahkan dengan waktu loading dan undloading, dimana waktu loading 40 menit dan waktu unloading 15 menit per toko tujuan.

Hasil perhitungan total waktu distribusi

Waktu distribusi $=12,54$ menit +40 menit $+(15$ menit $/$ toko $\times 7$ toko $)$ 
Waktu distribusi $=236,50$ menit

Hasil perhitungan waktu distribusi jadwal usulan ditunjukkan Tabel 5.

Tabel 5. Waktu Distribusi

\begin{tabular}{lcc}
\hline No & Rute & Waktu Distribusi (menit) \\
\hline 1 & I & 157,54 \\
2 & II & 257,38 \\
3 & III & 173,73 \\
4 & IV & 213,22 \\
5 & V & 230,24 \\
\hline
\end{tabular}

Berdasarkan penentuan rute, dilakukan pembagian wilayah distribusi untuk masing-masing sales. Batasan jam kerja tenaga sales yaitu pukul 06.00-12.00 WIB atau 6 jam dalam sehari. Pembagian sales disajikan Tabel 6.

Tabel 6. Penugasan sales

\begin{tabular}{cccc}
\hline Sales & Rute & $\begin{array}{c}\text { Waktu Distribusi } \\
\text { (menit) }\end{array}$ & $\begin{array}{c}\text { Waktu Distribusi } \\
\text { (jam) }\end{array}$ \\
\hline A & I dan III & 331,27 & 5,53 \\
B & II & 257,38 & 4,29 \\
C & IV & 213,22 & 3,58 \\
D & V & 230,24 & 3,87 \\
\hline
\end{tabular}

Adapun rute pengiriman yang didapatkan untuk masing-masing cluster ditunjukkan pada Gambar 2 hingga Gambar 6.

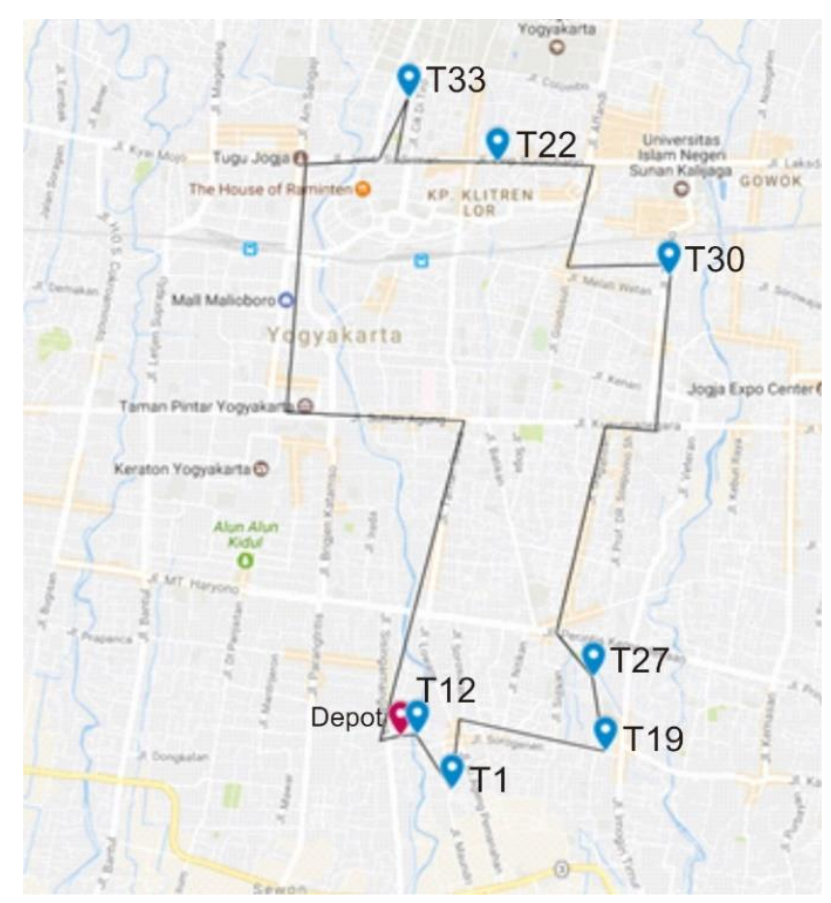

Gambar 2. Rute usulan I 


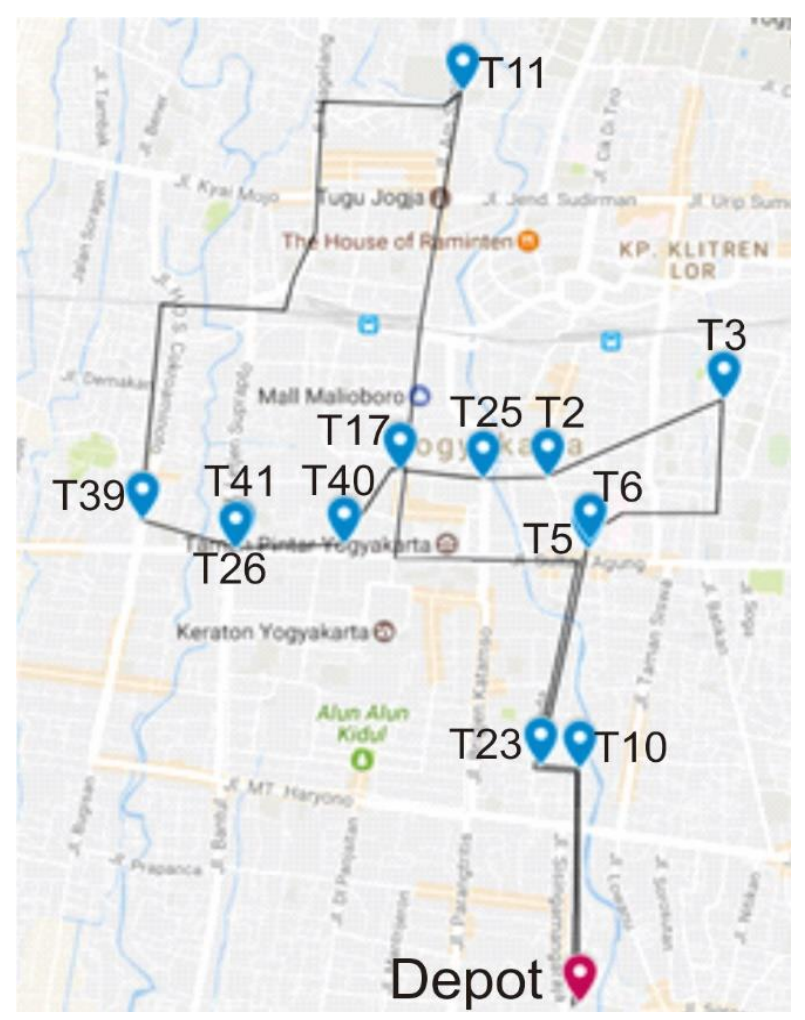

Gambar 3. Rute usulan II

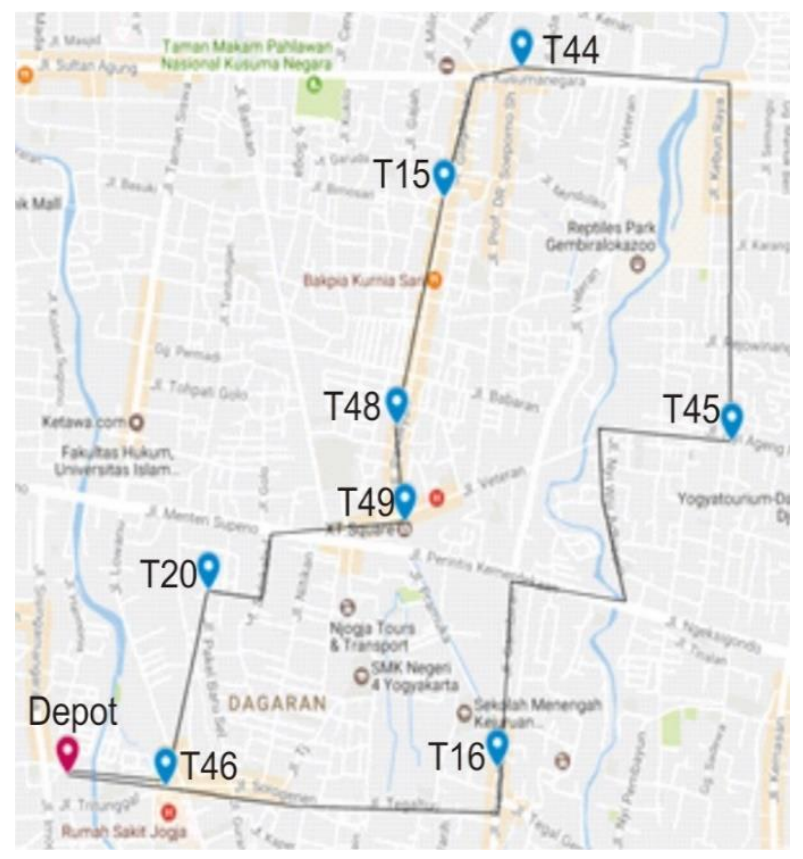

Gambar 4. Rute usulan III 


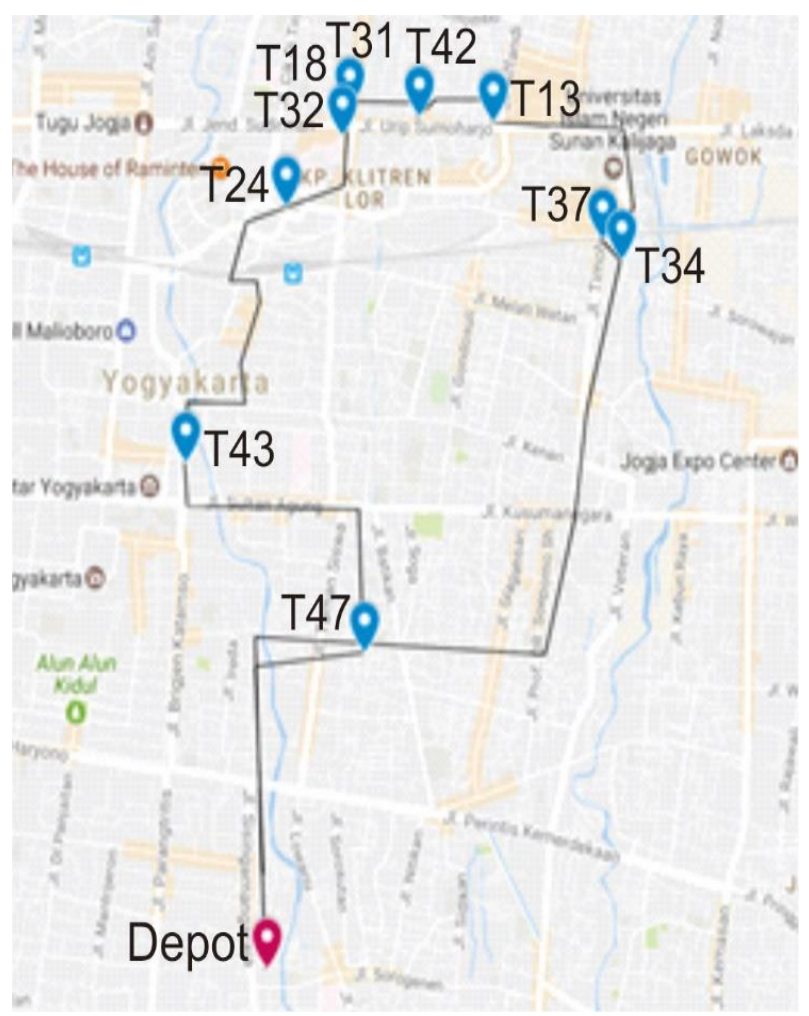

Gambar 5. Rute usulan IV

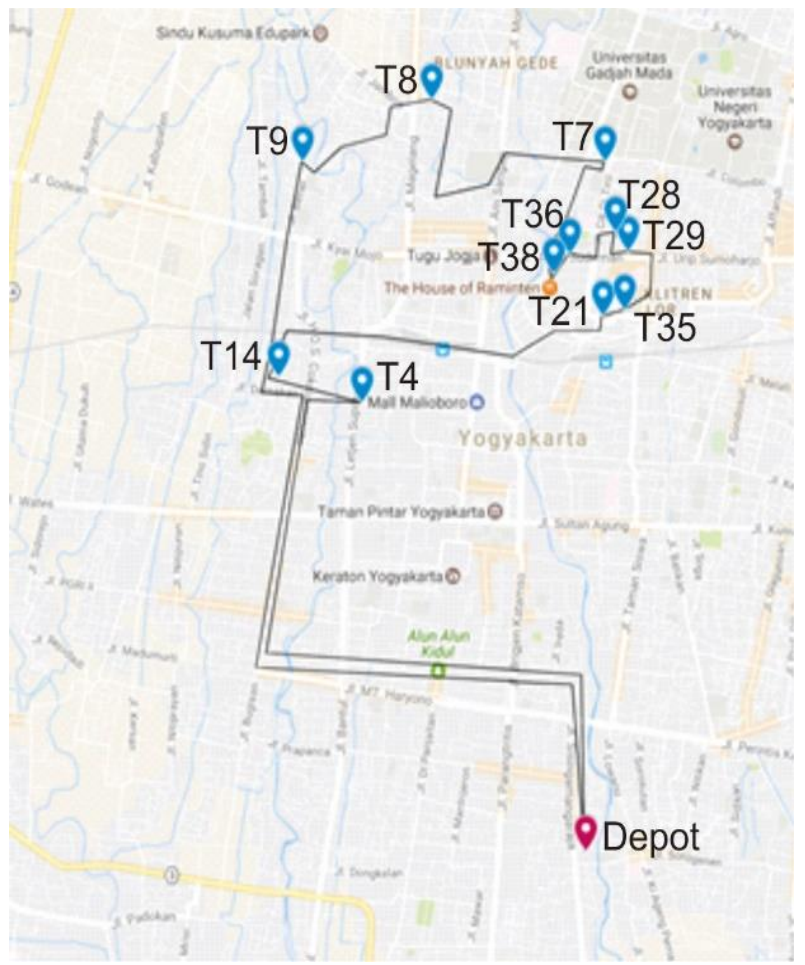

Gambar 6. Rute usulan V

Penataan rute pengiriman ini mampu mengurangi jarak tempuh dan waktu pengiriman. Pada kondisi awal jarak tempuhnya $115,39 \mathrm{~km}$, sementara pada hasil jarak tempuh berhasil diturunkan menjadi $64,3 \mathrm{~km}$. Kondisi ini disebabkan karena rute yang dilalui menawarkan jarak tempuh yang lebih kecil disbanding pola distribusi yang dilakukan sebelumnya. Perbanding jarak tempuh ditunjukkan pada Gambar 7. 


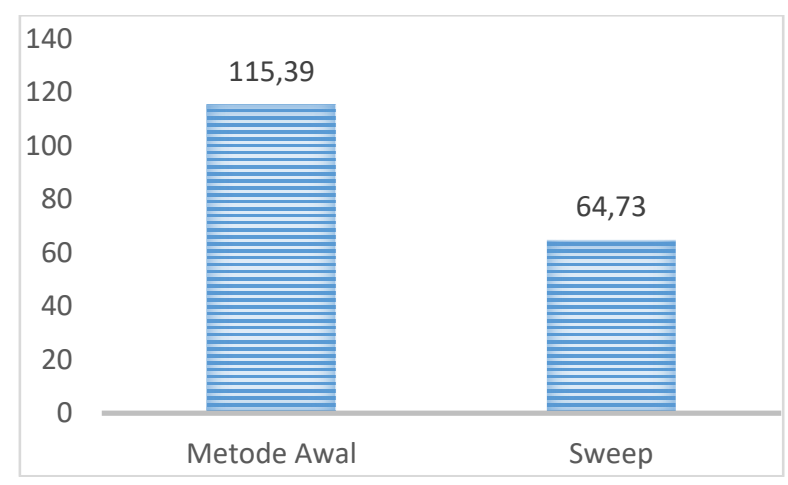

Gambar 7. Perbandingan jarak (Km)

Turunnya jarak tempuh juga berdampak pada perbandingan waktu distribusi. Dimana pada kondisi awal besarnya 1143,49 menit, sementara pada usulan hanya 1032,11 menit. Kondisi ini menunjukan bahwa penggunaan algoritma sweep dapat mempercepat proses pendistribusian produk ke masing-masing tujuan. Adapun perbandingannya ditunjukkan pada Gambar 8.

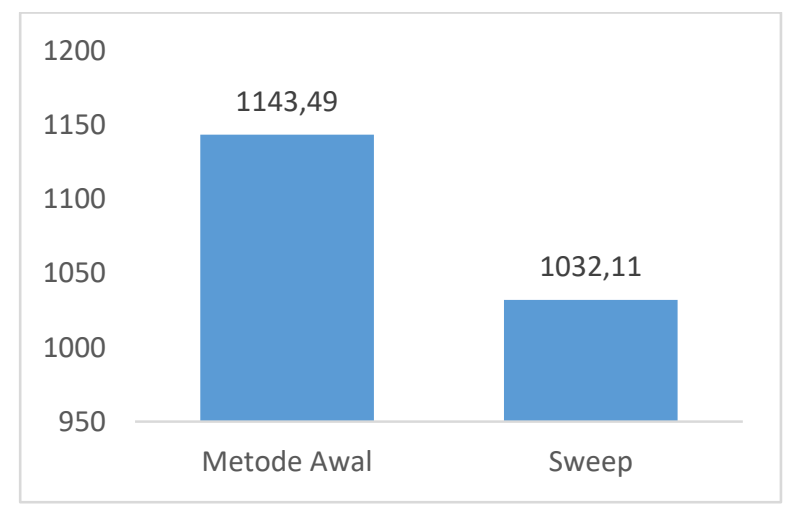

Gambar 8. Perbandingan kebutuhan waktu

Dampak lain yang ditimbulkan adalah menurunnya biaya. Pada kondisi awal biaya pengirimannya sebesar Rp. 56.539 sementara biaya pengiriman dengan metode Sweep hanya sebesar Rp. 31.717, sehingga terdapat penghematan $56,48 \%$. Perbandingan biaya dari rute distribusi menggunakan metode sweep dan metode awal ditunjukkan Gambar 9.

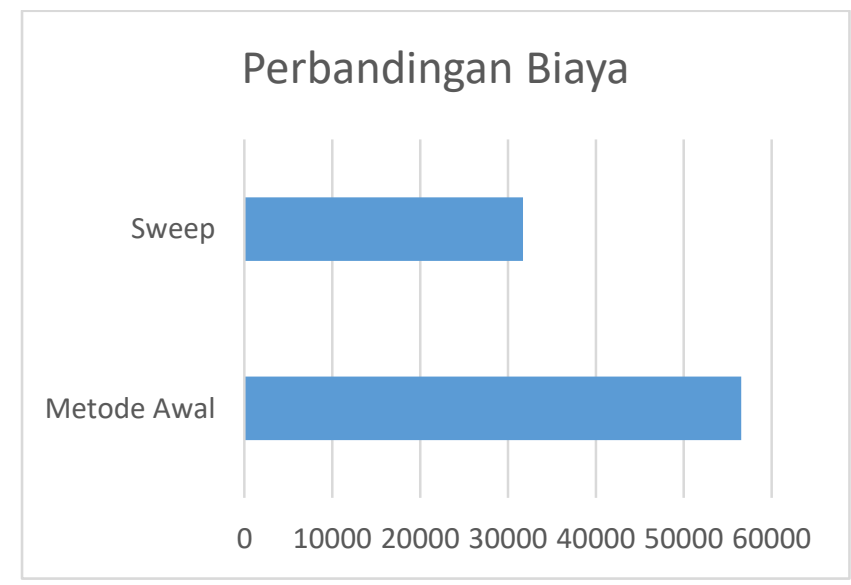

Gambar 9. Perbandingan biaya distribusi 
Berdasarkan pembahasan mengenai pendistribusian produk Sari Roti menggunakan Algoritma Sweep di wilayah kotamadya Yogyakarkta menunjukan tercapainya optimasi rute distribusi produk Sari Roti di CV Jogja Transport untuk wilayah kota madya Yogyakarta. Setelah dilakukan perhitungan menggunakan Algoritma Sweep dalam menyelesaikan didapatkan bahwa total biaya bahan bakar Rp. 31.717 sementara pada kondisi awal membutuhkan total biaya bahan bakar kendaraan perusahaan saat ini adalah Rp.56.539. Apabila dilakukan perhitungan persentase penghematan biaya bahan bakar diperoleh persentase sebesar $56,48 \%$.

\section{SIMPULAN}

Berdasarkan hasil pengolahan data usulan rancangan model pendistribusian produk Sari Roti di CV Jogja Transport menggunakan metode Algoritma Sweep dan analisis dari hasil pengolahan data jumlah pengangkutan yang direncanakan adalah Berdasarkan rute menggunakan Algoritma Sweep dapat mengurangi jumlah perjalanan distribusi yang sebelumnya 6 perjalanan menjadi 5 perjalanan.

Berdasarkan rute yang dibuat dengan Algoritma Sweep untuk optimasi rute distribusi produk Sari Roti di CV Jogja Transport untuk wilayah kota madya Yogyakarta mendapatkan biaya bahan bakar Rp. 31.717 dengan skema rute 5 kali perjalanan, sedangkan total biaya bahan bakar kendaraan perusahaan saat ini adalah Rp.56.539 dengan skema rute 6 kali perjalanan. Apabila dilakukan perhitungan persentase penghematan biaya bahan bakar diperoleh persentase sebesar $56,48 \%$.

\section{DAFTAR PUSTAKA}

Boonsam, P., Suthikarnnarunai, N., \& Rattanawong, W. (2013). Efficiency improvement for multi depot vehicle routing: A case study in cash distribution. Applied Mechanics and Materials. https://doi.org/10.4028/www.scientific.net/AMM.284-287.3667

Cahyaningsih, W. K., Sari, E. R., \& Hernawati, K. (2015). Penyelesaian Capacitated Vehicle Routing Problem (Cvrp) Menggunakan Algoritma Sweep Untuk Optimasi Rute Distribusi Surat Kabar Kedaulatan Rakyat. Seminar Nasional Matematika Dan Pendidikan Matematika.

Dondo, R., \& Cerdá, J. (2013). A sweep-heuristic based formulation for the vehicle routing problem with cross-docking. Computers and Chemical Engineering. https://doi.org/10.1016/j.compchemeng.2012.09.016

Dondo, R., \& Cerdá, J. (2015). The heterogeneous vehicle routing and truck scheduling problem in a multidoor cross-dock system. Computers and Chemical Engineering. https://doi.org/10.1016/j.compchemeng.2015.02.003

Hertrich, C., Hungerländer, P., \& Truden, C. (2019). Sweep Algorithms for the Capacitated Vehicle Routing Problem with Structured Time Windows. https://doi.org/10.1007/978-3-030-18500-8_17

IMRAN, A., \& OKDINAWATI, L. (2012). ADAPTATION OF THE VARIABLE NEIGHBORHOOD SEARCH HEURISTIC TO SOLVE THE VEHICLE ROUTING PROBLEM. Jurnal Teknik Industri. https://doi.org/10.22219/jtiumm.vol12.no1.10-15

Irnich, S., Toth, P., \& Vigo, D. (2014). Chapter 1: The Family of Vehicle Routing Problems. In Vehicle Routing. https://doi.org/10.1137/1.9781611973594.ch1

Kurniawan, I. S., Susanty, S., \& Adianto, H. (2014). Usulan Rute Pendistribusian Air Mineral Dalam Kemasan Menggunakan Metode Nearest Neighbour dan Clarke \& Wright Savings. Jurnal Online Institut Teknologi Nasional.

Nugroho, Y. A. (2019). Optimasi Model Pengiriman Bantuan Bencana Gempa Bumi di BPBD Kabupaten Bantul. SPEKTRUM INDUSTRI. https://doi.org/10.12928/si.v17i1.10882

Saraswati, R., Sutopo, W., \& Hisjam, M. (2017). PENYELESAIAN CAPACITATED VECHILE ROUTING PROBLEM DENGAN MENGGUNAKAN ALGORITMA SWEEP UNTUK PENENTUAN RUTE DISTRIBUSI KORAN : STUDI KASUS. Jurnal Manajemen Pemasaran. https://doi.org/10.9744/pemasaran.11.2.41-44

Steinhaus, M., Shirazi, A. N., \& Sodhi, M. (2015). Modified self organizing neural network algorithm for solving the Vehicle Routing Problem. Proceedings - IEEE 18th International Conference on Computational Science and Engineering, CSE 2015. https://doi.org/10.1109/CSE.2015.56

Wassan, N., \& Nagy, G. (2014). Vehicle Routing Problem with Deliveries and Pickups: Modelling Issues and Meta-heuristics Solution Approaches. International Journal of Transportation. https://doi.org/10.14257/ijt.2014.2.1.06 